\title{
Mediastinal Lymph Node Staging in Potentially Resectable Non-Small Cell Lung Cancer: A Prospective Comparison of CT and EUS/EUS-FNA
}

\author{
Ichiro Yasuda $^{a}$ Tatsuo Kato $^{\mathrm{b}}$ Fumihiro Asano $^{d}$ Kenichi Okubo $^{c}$ Salem Omar ${ }^{f}$ \\ Nobuo Kako ${ }^{e}$ Shigeo Yasudab Kimiyasu Sano ${ }^{b}$ Nib Soehendra ${ }^{f}$ \\ Hisataka Moriwaki ${ }^{a}$ \\ ${ }^{a}$ First Department of Internal Medicine, Gifu University Hospital, Departments of ${ }^{b}$ Pulmonary Medicine and \\ 'Thoracic Surgery, National Hospital Organization Nagara Medical Center, ${ }^{\mathrm{d}}$ Department of Pulmonary Medicine, \\ Gifu Prefectural General Medical Center, and e Department of Radiology, Kizawa Memorial Hospital, Gifu, Japan; \\ fDepartment of Interdisciplinary Endoscopy, University Medical Center Hamburg-Eppendorf, Hamburg, Germany
}

For editorial comment see p. 371

\section{Key Words}

Computed tomography • Endoscopic ultrasonography •

Endoscopic ultrasound-guided fine needle aspiration •

FDG-PET • Lung cancer staging • Mediastinal lymph node •

Non-small cell lung cancer

\begin{abstract}
Background: Mediastinal lymph node staging (N-staging) is essential to optimize the treatment in non-small cell lung cancer (NSCLC). Transesophageal endoscopic ultrasonography-guided fine needle aspiration (EUS-FNA) has recently been introduced as a complementary method. However, in most reports, EUS-FNA has been performed in patients who have demonstrated enlarged lymph nodes (LNs) on CT findings. The yield of EUS/EUS-FNA in patients without enlarged mediastinal LNs by CT has so far only been evaluated in a few reports. Aims: Our aim was to compare the diagnostic accuracy of CT and EUS with or without EUS-FNA (EUS/EUS-FNA) prospectively, for $\mathrm{N}$-stage in all patients with potentially resectable NSCLC, including patients with and without mediastinal LN enlargement based on CT findings. Methods: Eighty consecutive patients with potentially resectable NSCLC based on CT findings were enrolled in this prospec-
\end{abstract}

\section{KARGER}

Fax +41613061234 E-Mail karger@karger.ch www.karger.com
(C) 2009 S. Karger AG, Basel

$0025-7931 / 09 / 0784-0423 \$ 26.00 / 0$

Accessible online at:

www.karger.com/res tive comparative study, and underwent EUS/EUS-FNA. Results: Pathological N-stage was established in 78 patients, while in another 2 cases, malignant pleural effusion was proven by EUS-FNA, and we avoided further $\mathrm{N}$-staging. In the 78 patients, the prevalence of malignant mediastinal LNs was $21 \%$. The accuracy of EUS/EUS-FNA (91\%) was significantly higher than that of CT (71\%). The negative predictive value of EUS/EUS-FNA was $90 \%$. In addition, EUS-FNA identified 2 patients as N3 disease in 56 patients without mediastinal LN involvement on CT. Conclusions: EUS/EUS-FNA gave more accurate $\mathrm{N}$-staging in patients with possibly resectable NSCLC than CT, and is thus considered to be useful to determine the optimal treatment strategy.

Copyright $\odot 2009$ S. Karger AG, Basel

The annual incidence of lung cancer is more than 1 million worldwide, and it is now the most common malignancy in Japan as well as in Western countries. Mediastinal lymph node (LN) involvement is reported to be present in about one-third of those cases at the time of initial diagnosis, and a mediastinal LN staging ( $\mathrm{N}$-staging) of non-small cell lung cancer (NSCLC) is very important in choosing the treatment course [1-3]. CT is the

Ichiro Yasuda, $\mathrm{MD}, \mathrm{PhD}$

First Department of Internal Medicine

Gifu University Hospital

1-1 Yanagido, Gifu 501-1194 (Japan)

Tel. +81 58230 6308, Fax +81 58230 6310, E-Mail yasudaic@aol.com 
standard imaging modality used to define the extent and location of the primary lesion and to detect mediastinal LN enlargement. However, because of its insufficient diagnostic ability, additional imaging modalities have been requested. Recently, ${ }^{18} \mathrm{~F}$-fluorodeoxyglucose positron emission tomography (FDG-PET) has often been attempted for this purpose [4-6], and transesophageal endoscopic ultrasonography with or without fine needle aspiration (EUS/EUS-FNA) has also been evaluated as a valuable modality [6-21]. However, in most reports, EUSFNA was performed in the patients who had demonstrated enlarged lymph nodes on the CT findings [7-14]. The yield of EUS/EUS-FNA in patients without enlarged mediastinal LNs by CT has so far been evaluated in only a few reports [18-20]. We therefore compared these 2 modalities simultaneously in both patients with and without mediastinal LN enlargement based on the CT findings.

\section{Patients and Methods}

\section{Study Design}

This study was a prospective comparative study at 3 tertiary center hospitals: the Gifu University Hospital, the National Hospital Organization Nagara Medical Center, and the National Health Insurance Sekigahara Hospital.

The primary endpoint of this study was to compare the accuracy of CT and EUS/EUS-FNA. Secondary endpoints were the sensitivity, specificity, positive predictive value (PPV), and negative predictive value (NPV) for predicting the N-staging of CT and EUS/EUS-FNA. These values were also evaluated in FDGPET for reference.

\section{Sample Size}

The accuracy of CT has been estimated to be $67 \%$ from previously reported data $[6,11-13,15]$. Since a difference in accuracy by $20 \%$ was deemed to be clinically relevant and EUS/EUS-FNA improved accuracy by $20 \%$ in a preceding feasibility study (data not shown), we calculated that, with an $\alpha$-error of 0.05 and a $\beta$ error of 0.20 , a minimum sample size of 69 patients would be required to show such a difference. Considering the number of patients who might not complete the study, the final number of the enrolled cases was determined to be 80 .

\section{Patients}

Eighty consecutive patients with potentially resectable NSCLC, who were referred to our hospitals and met the inclusion criteria below, were enrolled into this study. At our institutions, patients with N2 (stage IIIA) were considered operable, as well as those with stages I and II. These patients underwent lobectomy with complete thoracic lymphadenectomy. The inclusion criteria of this study were: (1) patients with newly diagnosed or suspected NSCLC based on CT and bronchoscopic findings, and (2) the clinical stage was judged to be below T4, any N, M0 according to the TNM subsets [22] based on CT findings. They included both patients with and without swollen mediastinal LNs, and re- gardless of location of the LNs. Stage-IIIB subjects due to contralateral mediastinal LNs (N3) were also included because if the contralateral LNs were pathologically negative by EUS-FNA, they would be below N3 and thus might be resectable. The exclusion criteria were: (1) patients with poor medical conditions of grades 4 and 5, according to American Society of Anesthesiologists classification; (2) patients with bleeding tendency and coagulopathy, and (3) cases in which the patient refused surgery.

After written informed consent was obtained, the patients underwent EUS/EUS-FNA. FDG-PET was also performed in all patients before EUS/EUS-FNA. In cases eventually diagnosed to be resectable, a surgical operation was performed. If N3 was proven histopathologically by EUS-FNA, surgical procedures were avoided. In cases diagnosed to be N3 (contralateral mediastinal LNs) by CT or FDG-PET but below N3 by EUS/EUS-FNA, a mediastinoscopy was performed just before the surgical operation, and if the result was pathologically negative, a subsequent surgery was performed.

Each institute's review board for human research approved this study protocol. This study was conducted in accordance with the Declaration of Helsinki.

\section{Methods}

The CT staging was judged by 2 expert pulmonologists (T.K., F.A.), and the FDG-PET findings were reviewed by an expert radiologist (N.K.). An experienced endosonographer (I.Y.) performed EUS/EUS-FNA. They were blinded to the results of other examinations. The mediastinal LNs were coded according to the American Joint Committee on Cancer staging system [23].

Computed Tomography. All patients underwent a chest and upper abdominal CT. A multi-detector row CT scanner (LightSpeed Ultra, GE Medical Systems, Milwaukee, Wisc., USA) with a detector configuration of $8 \times 25 \mathrm{~mm}$ was used with a helical pitch of 1.35, and the images were reconstructed from $5-\mathrm{mm}$ thick images. Scanning was commenced with a delay of 30 and $120 \mathrm{~s}$ after $100 \mathrm{ml}$ of non-iodinated contrast medium was administered intravenously at a rate of $2 \mathrm{ml} / \mathrm{s}$. We defined LNs larger than $10 \mathrm{~mm}$ across the short axis to be metastatic, except at the subcarinal level where the size for considering an LN to be normal was $12 \mathrm{~mm}$ [24].

FDG-PET. This was performed on all patients at the PET Center, Kizawa Memorial Hospital, using GE PET Advance NX/i (GE Medical Systems) with whole-body attenuation. After subjects had fasted for at least $6 \mathrm{~h}$, and their blood glucose levels had been confirmed to be within normal limits, they were injected with an intravenous dose of $5 \mathrm{MBq} / \mathrm{kg}$ FDG. The emission study commenced $60 \mathrm{~min}$ later, and lasted for $20 \mathrm{~min}$. The FDG uptake in the mediastinal lymph node was examined first, based on visual interpretation, and a standardized uptake value above 3.0 was considered to be positive for a definite localized area in the mediastinum.

EUS/EUS-FNA. We used an electronic linear scanning echoendoscope (GF-UC240P-AL5, Olympus, Tokyo, Japan) equipped with a processor with color Doppler function (SSD-5000, Aloka, Tokyo, Japan). After the patient was sedated using a combination of midazolam and pentazocine, the echoendoscope was advanced to the stomach, and the left adrenal gland, celiac region and left lobe of the liver were observed. The echoendoscope was then gradually withdrawn to the esophagus, and the following regions were evaluated: pulmonary ligament, paraesophageal, subcari- 
nal, lower paratracheal, subaortic and upper paratracheal [25]. After the initial orientation, LNs larger than $5 \mathrm{~mm}$ across the short axis were intended for FNA. This size criterion was defined because, in our experience, it is difficult to obtain pathological materials by EUS-FNA from LNs smaller than $5 \mathrm{~mm}$. If multiple LNs were detected at the same level (region), then FNA was performed on the largest LN, that showed a round shape, a homogeneous hypoechoic image, and sharp distinctive borders [26, 27]. However, when it was difficult to choose only $1 \mathrm{LN}$, then $2 \mathrm{LNs}$ would be punctured. The puncture was made using either a 22gauge or 19-gauge needle (EchoTip, Wilson-Cook, Winston-Salem, N.C., USA). Since there are no pathologists on-site at our institutions, pathological samples were obtained in all levels of the LNs, and were sent to pathologists thereafter. If pleural effusion was detected by EUS, then the fluid was obtained by FNA and was immediately sent to the pathologist. If the cytopathological assessment of the fluid showed malignancy, we avoided further FNA for N-staging. The cytopathological results of FNA samples were classified into positive, suspicious and negative, and only positive was defined as 'positive for metastasis'.

\section{Data Analysis}

The final pathological $\mathrm{N}$-staging was determined from results of mediastinoscopy, thoracoscopy, open surgery or EUS-FNA. The N-staging was divided into the following 3 categories: N0/N1, $\mathrm{N} 2$ and N3. We calculated the accuracy and its 95\% CI, and performed comparisons using the MacNemar's test, with a p value of less than 0.05 considered to indicate a significant difference. The sensitivity, specificity, PPV, and NPV were calculated after counting the number of true positives, true negatives, false positives and false negatives according to each modality. The number of false positives was counted as the number of patients with a higher N-stage in comparison to the final diagnosis, and the number of false negatives was counted as the number of patients with a lower $\mathrm{N}$-stage compared to the final diagnosis. The software program used was the JMP, version 7 (SAS Institute, Cary, N.C., USA).

\section{Results}

Eighty patients were enrolled in this study between March 2004 and February 2006. Their baseline characteristics are outlined in table 1 . They included 49 patients without any mediastinal LNs (N0), 10 patients with N1, 18 patients with $\mathrm{N} 2$ and 3 patients with N3 on CT findings. All patients had undergone bronchoscopy, and 45 patients had been proven to have NSCLC, with a histological diagnosis of adenocarcinoma in 33, squamous cell carcinoma in 11 and adenosquamous carcinoma in 1. However, the remaining 35 patients showed negative biopsies or normal bronchoscopic findings.

Following enrollment, FDG-PET and EUS were performed in all patients as shown in figure 1. EUS did not detect any mediastinal LNs larger than $5 \mathrm{~mm}$ in 14 patients, and their N-stage was judged as N0/N1. EUS de-
Table 1. Baseline characteristics of the enrolled patients

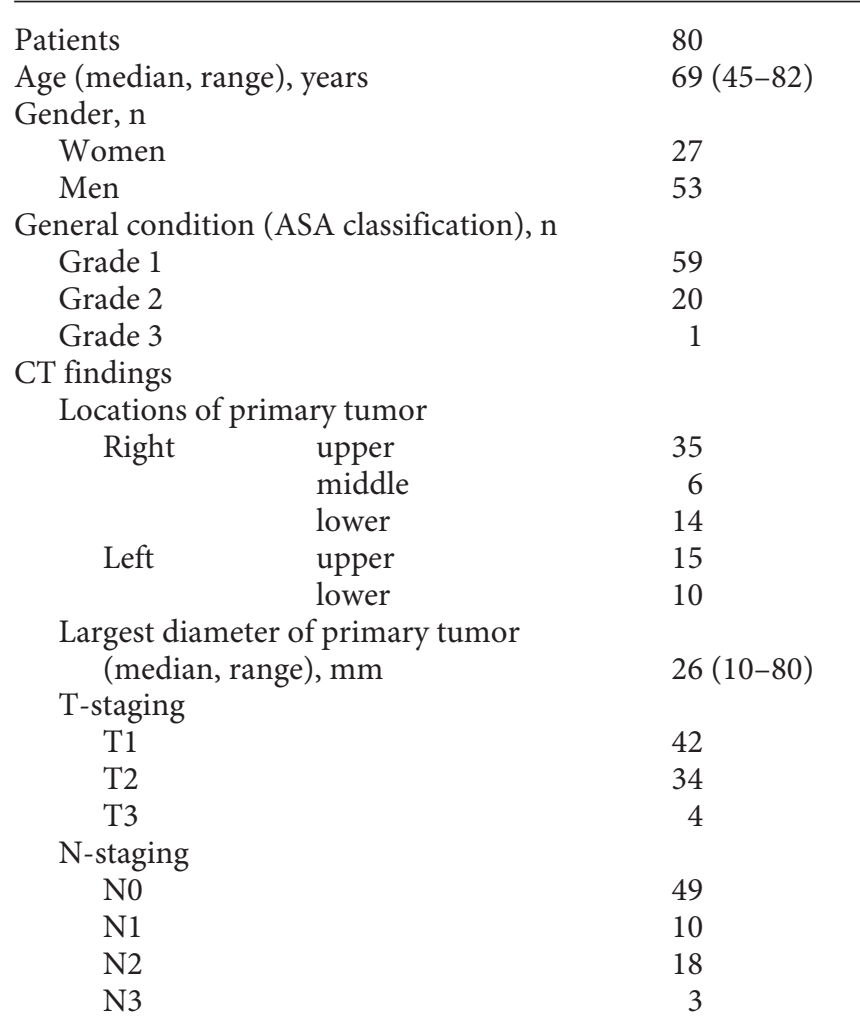

tected LNs larger than $5 \mathrm{~mm}$ in 66 patients and, simultaneously, a small amount of pleural effusion in 2 patients. Cytopathological samples of the effusion were obtained by EUS-FNA and showed malignancy. These 2 patients were judged as non-resectable, and FNA for N-staging was avoided. Thus, EUS-FNA was performed in the remaining 64 patients for $\mathrm{N}$-staging. The locations of the punctured LNs were level 2L in 3, level $2 \mathrm{R}$ in 2 , level $4 \mathrm{~L}$ in 36 , level $4 \mathrm{R}$ in 5 , level 5 in 2 , level 7 in 57 and level 8 in 5 patients. In the right lower paratracheal region (level $4 \mathrm{R})$, it is difficult to image the whole area due to the scatter from the air-filled trachea. However, bending the endoscope's tip upward thus makes it somewhat easier to assess the area, and it therefore becomes possible to assess at least the area around azygos arch (fig. 2). The subaortic region (level 5) can be assessed by EUS, but the puncture of $\mathrm{LN}$ at this location is often difficult because this site is far from the esophagus and adjacent to the aortic arch and the pulmonary artery. However, whether the puncture approach is possible or not depends on the size and the location of LN. We attempted to carry out FNA here only in cases in which the puncture could be safely per- 
Fig. 1. Structure of the process to reach final pathological diagnosis. NSCLC $=$ Nonsmall cell lung cancer; LN = lymph node. a Avoided N-staging by EUS-FNA and final $\mathrm{N}$-staging.

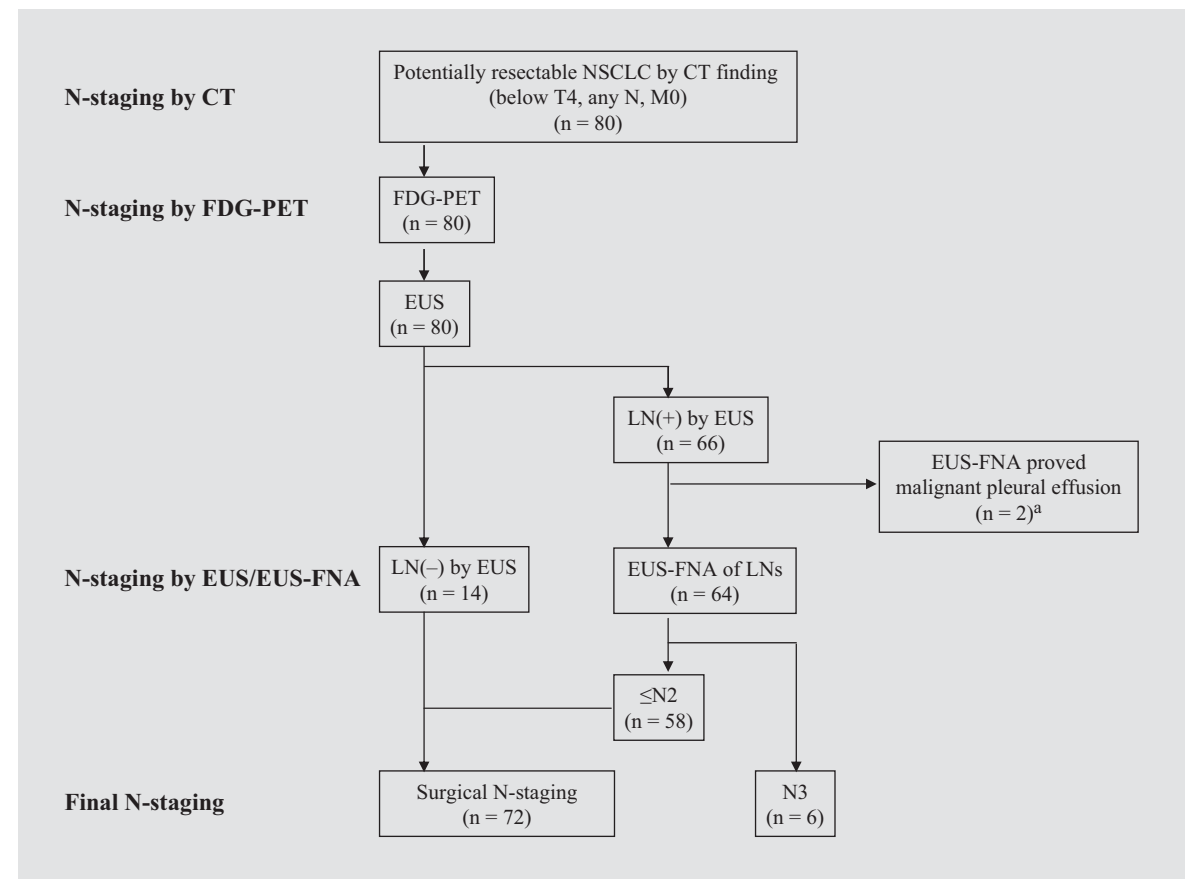

formed (fig. 3). The mean number of LN stations sampled per patient was 1.7: the $\mathrm{LN}$ was punctured at single station in 27 , two stations in 29 , three stations in 7 , and four stations in 1 patient. Multiple LNs were punctured at the same stations in 11 patients, thus a total of $121 \mathrm{LN}$ samples were obtained. The median short axis of the LNs was $7 \mathrm{~mm}(5-26 \mathrm{~mm})$. The mean number of needle passes was 1.3 (range 1-3). The pathological results were positive in $14 \mathrm{LNs}$, negative in $107 \mathrm{LNs}$, and suspicious in none. Thus, 6 patients were diagnosed to be $\mathrm{N} 3$ by pathological assessment of FNA samples, while others were $\leq \mathrm{N} 2$ (fig. 1). There were no lesions suspected of liver metastasis on the EUS in any patient. However, a mass was detected in the left adrenal gland in 2 patients, and the FNA diagnosis was adenoma in both cases. After excluding 6 patients with $\mathrm{N} 3$ disease and 2 patients with malignant pleural effusion, the remaining 58 patients were scheduled to undergo surgery (fig. 1).

In $\mathrm{LN}(-)$ patients with EUS, 4 have been suspected to be $\mathrm{N} 3$ based on the CT or FDG-PET, and they underwent mediastinoscopy with or without thoracoscopy. Fortunately, N3 was ruled out in all 4 patients, and subsequent surgical operations were thus performed in all $\mathrm{LN}(-)$ patients by EUS (fig. 1).

After surgery in a total of 72 patients, 67 were diagnosed to have NSCLC, with a histological diagnosis of adenocarcinoma in 46, squamous cell carcinoma in 18 and adenosquamous carcinoma in 3 . Five patients were diagnosed to have benign diseases, tuberculosis in 3 and inflammatory pseudotumor in 2 . However, these 5 patients with a final diagnosis of benign diseases were also included in the assessment of $\mathrm{N}$-staging. As a result, the final data analysis was assessed in 78 patients.

\section{Comparison of CT and EUS/EUS-FNA}

The raw data of the N-staging in the 78 patients, including 73 NSCLC and 5 benign cases, based on CT, FDG-PET and EUS/EUS-FNA are shown in figure 4 and table 2. As summarized in tables 3 and 4 , the accuracies of CT and EUS/EUS-FNA were 71\% (95\% CI 60-80\%) and $91 \%(83-96 \%)$, respectively. There was a significant statistical difference between EUS/EUS-FNA and CT ( $\mathrm{p}=0.0003$ ). The sensitivity, specificity, PPV and NPV of CT were 27, 81, 25 and 82\%, respectively, and those of EUS/EUS-FNA were 56, 100, 100 and 90\%, respectively. For reference purposes, the accuracy, sensitivity, specificity, PPV and NPV of FDG-PET were 77, 25, 90, 40 and $82 \%$.

As shown in figure 4, EUS-FNA found 2 patients to have N3 disease among the 56 patients in whom mediastinal LNs were not detected on CT and FDG-PET. In addition, EUS-FNA correctly denied mediastinal LN involve- 

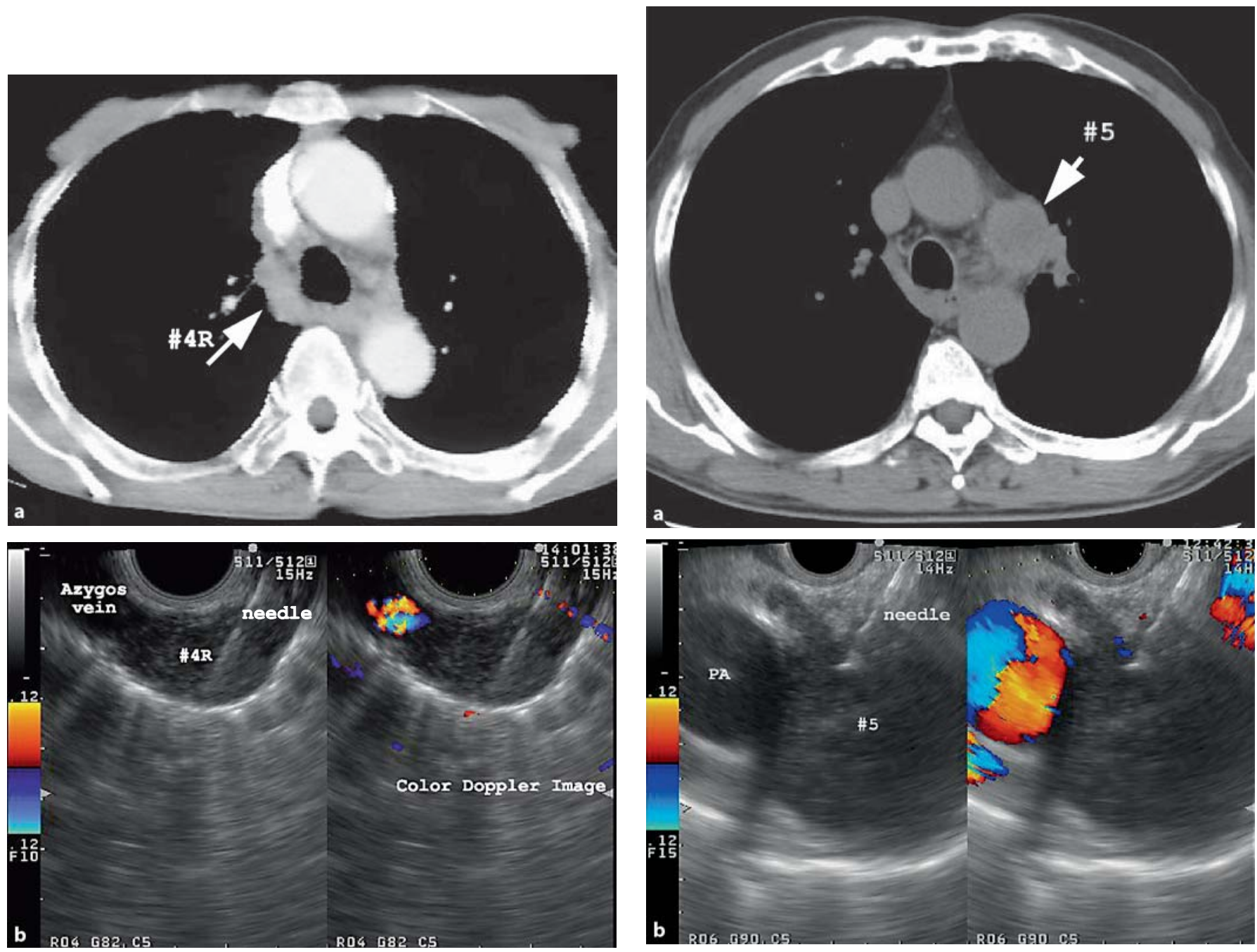

Fig. 2. A case of NSCLC with lymph node swelling at level $4 \mathrm{R}$. a The contrast-enhanced CT image shows an enlarged lymph node just above the azygos arch (arrow). b EUS-FNA was performed on the lymph node. The left image is a fundamental image and the right image is an image with color Doppler function.

ment in 13 of 22 patients who had been suspected of having mediastinal LN involvement on either CT or FDG-PET.

On the other hand, 7 patients were false-negative by EUS-FNA in this study. The positive LN was not detected by EUS in 4 patients: the location was at level $4 \mathrm{R}$ (pretracheal) in 3 and at level 6 in 1. In the remaining 3 patients, although the LNs were punctured, the pathological results were negative.

\section{Complications}

Mediastinal hematoma occurred in 1 (1.5\%) of 66 patients who underwent EUS-FNA, but it resolved after a

Fig. 3. A case of NSCLC with lymph node swelling at level 5. a The CT image shows an enlarged lymph node at level 5 (arrow). b EUS-FNA was performed on the lymph node. PA = Right pulmonary artery.

conservative treatment of fasting and bed rest. The surgical operation for NSCLC was performed 7 days later as scheduled.

\section{Discussion}

$\mathrm{CT}$ is currently recommended to evaluate the $\mathrm{N}$-stage of NSCLC, but its diagnostic accuracy is not sufficient [5]. FDG-PET has also been used for this purpose recently, and several studies demonstrated FDG-PET to be significantly superior to CT $[4,6]$. However, FDG-PET still has 
Table 2. Mediastinal lymph node staging by CT, FDG-PET and EUS/EUS-FNA

\begin{tabular}{llrll}
\hline & & \multicolumn{3}{c}{ Final diagnosis } \\
\cline { 3 - 5 } & & N0/N1 & N2 & N3 \\
\hline CT & N0/N1 & 51 & 5 & 2 \\
& N2 & 9 & 4 & 4 \\
& N3 & 2 & 1 & 0 \\
\hline FDG-PET & N0/N1 & 56 & 6 & 3 \\
& N2 & 1 & 4 & 3 \\
& N3 & 5 & 0 & 0 \\
\hline EUS/EUS-FNA & N0/N1 & 62 & 7 & 0 \\
& N2 & 0 & 3 & 0 \\
& N3 & 0 & 0 & 6 \\
\hline
\end{tabular}

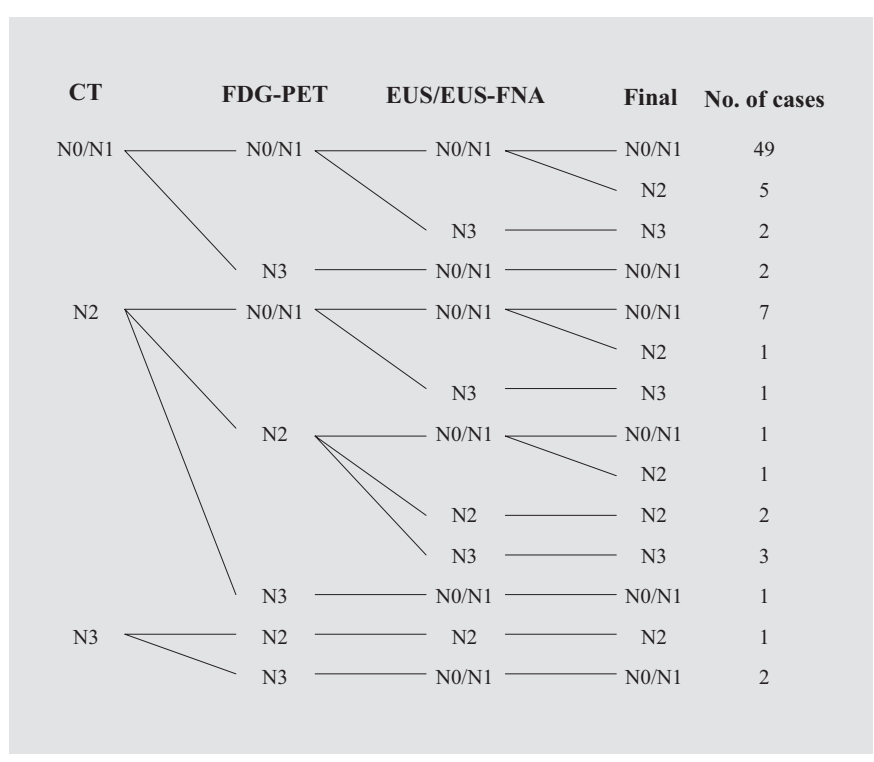

Fig. 4. The raw data of the $\mathrm{N}$-staging in the 78 patients based on the CT, FDG-PET and EUS/EUS-FNA findings.

a problem of false-positive and false-negative results. Therefore, current guidelines describe that NSCLC patients with suspected LN involvement should undergo tissue sampling for pathological confirmation before surgical interventions [1-3]. For this aim, transbronchial needle aspiration (TBNA) has been sometimes attempted, but the procedure is not easy and the diagnostic yield is not sufficient $[28,29]$. Recent surgical and mediastinoscopic techniques for $\mathrm{N}$-staging, such as transcervical extended mediastinal lymphadenectomy (TEMLA)
Table 3. Comparison of CT, FDG-PET, and EUS/EUS-FNA to the final diagnosis

\begin{tabular}{lllll}
\hline Tests & $\begin{array}{l}\text { True } \\
\text { positive }\end{array}$ & $\begin{array}{l}\text { True } \\
\text { negative }\end{array}$ & $\begin{array}{l}\text { False } \\
\text { positive }\end{array}$ & $\begin{array}{l}\text { False } \\
\text { negative }\end{array}$ \\
\hline CT & 4 & 51 & 12 & 11 \\
FDG-PET & 4 & 56 & 6 & 12 \\
EUS/EUS-FNA & 9 & 62 & 0 & 7 \\
\hline
\end{tabular}

Data represent number of patients. True positive = number of patients with identical $\mathrm{N}$-stage in malignant lesions; true negative $=$ number of patients with identical $\mathrm{N}$-stage in benign lesions; false positive $=$ number of patients with a higher $\mathrm{N}$-stage compared to the final diagnosis; false negative $=$ number of patients with a lower $\mathrm{N}$-stage compared to the final diagnosis.

and video-assisted mediastinoscopic lymphadenectomy (VAMLA), have become more accurate [30,31], but these procedures are still invasive, costly and require general anesthesia, as well as a long time and substantial manpower.

Transesophageal EUS is generally performed on an outpatient basis. It delivers a high-resolution image by itself and, furthermore, enables simultaneous tissue sampling. In the last decade, many studies have evaluated the usefulness of EUS-FNA in the N-staging of NSCLC with promising results, and several comparative studies revealed that EUS-FNA was superior to CT $[6,11-13,15]$. However, in most reports, EUS-FNA was performed in the patients who had demonstrated enlarged lymph nodes on the CT findings [11-13].

Eloubeidi et al. [21] compared the diagnostic ability of EUS-FNA to that of FDG-PET and CT. In their study, 104 consecutive patients with suspicious LNs based on CT or FDG-PET were prospectively evaluated by EUS-FNA. They concluded that EUS-FNA was more accurate and had a higher positive predictive value than CT or FDGPET in confirming the posterior mediastinal involvement. However, as the authors described, a limitation of their study was that the subjects were patients with suspicious LNs either on CT or on FDG-PET only, and they did not evaluate patients who were CT and FDG-PET negative. On the other hand, another study reported that EUS-FNA detected mediastinal involvement in $42 \%$ of patients whose CT findings were falsely negative [15].

Therefore, in our study, EUS was attempted on all patients with possibly resectable NSCLC, regardless of the $\mathrm{N}$-staging results based on CT or FDG-PET. As a result, 
Table 4. Comparison of diagnostic results of CT, FDG-PET, and EUS/EUS-FNA

\begin{tabular}{llcccr}
\hline Tests & Accuracy & Sensitivity & Specificity & PPV & NPV \\
\hline CT & $71(60-80)$ & $27(11-52)$ & $81(70-89)$ & $25(10-49)$ & $82(71-90)$ \\
FDG-PET & $77(66-85)$ & $25(10-49)$ & $90(80-95)$ & $40(17-69)$ & $82(72-90)$ \\
EUS/EUS-FNA & $91(83-96)^{*}$ & $56(33-77)$ & $100(94-100)^{*}$ & $100(70-100)^{*}$ & $90(81-95)$ \\
\hline
\end{tabular}

Data are presented as \% (95\% CI). ${ }^{*}$ Rate is significantly higher than those of CT and FDG-PET.

our study included 56 patients who were CT and FDGPET negative, and EUS-FNA proved N3 disease in 2 patients among them. On the other hand, EUS-FNA correctly ruled out mediastinal $\mathrm{LN}$ involvement in 13 of 22 patients who had been suspected of having mediastinal LN involvement on CT. Taken together, our study demonstrated the accuracy of EUS/EUS-FNA (91\%) to be significantly superior to that of CT (71\%). It illustrates that EUS/EUS-FNA should be added for the preoperative Nstaging of patients with potentially resectable NSCLC.

However, we must also mention that EUS/EUS-FNA has a limitation, namely, the imperfect false-negative rate, which was seen in 7 cases (9\%) in our study. This is likely to have resulted from both sampling error due to LNs with micrometastases and the visual inability in the anterior mediastinum. The mean number of needle passes was 1.3 (range 1-3) per lesion in our study, and the number of needle pass was only once in 88 of the 121 lesions, including the 3 false-negative cases. These data may indicate that repeated needle passes can reduce the false-negative rate, as reported in a previous paper [32]. Regarding the inaccessibility of the pretracheal area, we could not detect by EUS the pretracheal LNs in 3 patients, and they resulted in false negatives. Therefore, in cases with suspected LNs in the pretracheal area based on CT or FDG-PET, another option should be added to investigate such involvement. For this purpose, an endobronchial ultrasound-guided TBNA (EBUS-TBNA), which is capable of providing pathological information from the anterior tracheal and hilar regions, has recently been introduced. A combined approach with both EUS-FNA and EBUS-TBNA may thus make it possible to achieve near-complete minimally invasive mediastinal N-staging in patients with suspected NSCLC [33-36]. However, the anterior mediastinum (level $3 \mathrm{~A}$ ) is still inaccessible even using EBUS or mediastinoscopy. For this area, another option, such as thoracoscopy and TEMLA, should therefore be considered $[3,30]$.

EUS/EUS-FNA for Mediastinal Lymph Node Staging in NSC Lung Cancer
In addition, this study has several other limitations. First, contralateral LN positive (N3) by EUS-FNA was defined as $\mathrm{N} 3$ on the final $\mathrm{N}$-staging because the diagnosis was based on the pathological findings and surgical $\mathrm{N}$ staging was thus considered to be ethically unacceptable in this situation. Therefore, a false positive of EUS-FNA could not be detected in this setting, which is probably advantageous for EUS-FNA and related to its high PPV.

Second, our study population included all potentially resectable NSCLC patients, because the aim of this study was to prospectively evaluate the diagnostic accuracy of CT and EUS/EUS-FNA in this setting. For this aim, we did not set limits on N-stage by CT findings. However, $\mathrm{N}$-staging was N0/1 in the final diagnosis of 62 (79\%) of 78 patients. Therefore, such a low prevalence of mediastinal involvement might influence the assessment of the diagnostic results, and the presence of only small LNs probably influenced the low sensitivity of CT (27\%) in our study. In fact, the short axis of the LNs finally diagnosed as positive was smaller than $10 \mathrm{~mm}$ in 12 (75\%) of 16 patients with mediastinal involvement. In addition, EUS-FNA should be able to detect smaller LNs than CT or FDG-PET, but the sensitivity of EUS/EUS-FNA in our study (56\%) was still lower than that described in previous reports [10]. This may be due to the fact that our subjects included the patients regardless of location of the LNs, while most of previous studies included only patients who were most likely to have LNs accessible by the procedure. Indeed, 4 of 7 false-negative patients had positive LNs at levels inaccessible by EUS.

Third, our inclusion criteria did not require a pathological confirmation of NSCLC. The pathological diagnosis by bronchoscopy is often difficult, especially in small lesions. Therefore, we included all patients suspected of having potentially resectable NSCLC on the CT findings to avoid any selection bias in this step. As a result, our data analysis included 5 patients who were finally diagnosed to have benign diseases. This resulted in 
the specificity and the PPV of CT being lower, because all of them had enlarged mediastinal LNs and were counted as false positives. On the other hand, EUS-FNA correctly diagnosed the LNs as either malignant or benign. This situation was thus considered to be advantageous for EUS-FNA.
In conclusion, EUS/EUS-FNA is a more accurate procedure than CT, and should be added as a tool for the preoperative N-staging of NSCLC. However, it also has a limitation since some locations remain inaccessible, therefore a complementary method is thus considered to be necessary to achieve complete $\mathrm{N}$-staging in patients with potentially resectable NSCLC.

\section{References}

$\longrightarrow 1$ Silvestri GA, Gould MK, Margolis ML, Tanoue LT, McCrory D, Toloza E, Detterbeck F: Noninvasive staging of non-small cell lung cancer: ACCP evidenced-based clinical practice guidelines (2nd edition). Chest 2007;132:178S-201S.

-2 Detterbeck FC, Jantz MA, Wallace M, Vansteenkiste J, Silvestri GA: Invasive mediastinal staging of lung cancer: ACCP evidence-based clinical practice guidelines (2nd edition). Chest 2007;132:202S-220S.

-3 De Leyn P, Lardinois D, Van Schil PE, RamiPorta R, Passlick B, Zielinski M, Waller DA, Lerut T, Weder W: Ests guidelines for preoperative lymph node staging for non-small cell lung cancer. Eur J Cardiothorac Surg 2007;32:1-8.

-4 Gupta NC, Graeber GM, Bishop HA: Comparative efficacy of positron emission tomography with fluorodeoxyglucose in evaluation of small $(<1 \mathrm{~cm})$, intermediate (1 to 3 $\mathrm{cm})$, and large $(>3 \mathrm{~cm})$ lymph node lesions. Chest 2000;117:773-778.

5 Toloza EM, Harpole L, McCrory DC: Noninvasive staging of non-small cell lung cancer: a review of the current evidence. Chest 2003; 123:137S-146S.

-6 Fritscher-Ravens A, Bohuslavizki KH, Brandt L, Bobrowski C, Lund C, Knofel WT, Pforte A: Mediastinal lymph node involvement in potentially resectable lung cancer: comparison of CT, positron emission tomography, and endoscopic ultrasonography with and without fine-needle aspiration. Chest 2003;123:442-451.

7 Wallace MB, Fritscher-Ravens A, Savides TJ: Endoscopic ultrasound for the staging of non-small-cell lung cancer. Endoscopy 2003; 35:606-610.

8 Fritscher-Ravens A: Endoscopic ultrasound evaluation in the diagnosis and staging of lung cancer. Lung Cancer 2003;41:259-267.

$\checkmark$ Wallace MB, Woodward TA, Raimondo M: Endoscopic ultrasound and staging of nonsmall cell lung cancer. Gastrointest Endosc Clin N Am 2005;15:157-167.

10 Micames CG, McCrory DC, Pavey DA, Jowell PS, Gress FG: Endoscopic ultrasoundguided fine-needle aspiration for non-small cell lung cancer staging: a systematic review and metaanalysis. Chest 2007;131:539-548.
11 Silvestri GA, Hoffman BJ, Bhutani MS, Hawes RH, Coppage L, Sanders-Cliette A, Reed CE: Endoscopic ultrasound with fineneedle aspiration in the diagnosis and staging of lung cancer. Ann Thorac Surg 1996;61: 1441-1445.

12 Gress FG, Savides TJ, Sandler A, Kesler K, Conces D, Cummings O, Mathur P, Ikenberry S, Bilderback S, Hawes R: Endoscopic ultrasonography, fine-needle aspiration biopsy guided by endoscopic ultrasonography, and computed tomography in the preoperative staging of non-small-cell lung cancer: a comparison study. Ann Intern Med 1997; 127:604-612.

$>13$ Wiersema MJ, Vazquez-Sequeiros E, Wiersema LM: Evaluation of mediastinal lymphadenopathy with endoscopic US-guided fine-needle aspiration biopsy. Radiology 2001;219:252-257.

14 Annema JT, Versteegh MI, Veselic M, Voigt P, Rabe KF: Endoscopic ultrasound-guided fine-needle aspiration in the diagnosis and staging of lung cancer and its impact on surgical staging. J Clin Oncol 2005;23:83578361 .

15 Wallace MB, Silvestri GA, Sahai AV, Hawes RH, Hoffman BJ, Durkalski V, Hennesey WS, Reed CE: Endoscopic ultrasound-guided fine needle aspiration for staging patients with carcinoma of the lung. Ann Thorac Surg 2001;72:1861-1867.

16 Larsen SS, Vilmann P, Krasnik M, Dirksen A, Clementsen P, Maltbaek N, Lassen U, Skov BG, Jacobsen GK: Endoscopic ultrasound guided biopsy performed routinely in lung cancer staging spares futile thoracotomies: preliminary results from a randomised clinical trial. Lung Cancer 2005;49:377385.

17 Annema JT, Versteegh MI, Veselic M, Welker L, Mauad T, Sont JK, Willems LN, Rabe KF: Endoscopic ultrasound added to mediastinoscopy for preoperative staging of patients with lung cancer. JAMA 2005;294: 931-936.

18 Wallace MB, Ravenel J, Block MI, Fraig M, Silvestri G, Wildi S, Schmulewitz N, Varadarajulu S, Roberts S, Hoffman BJ, Hawes $\mathrm{RH}$, Reed CE: Endoscopic ultrasound in lung cancer patients with a normal mediastinum on computed tomography. Ann Thorac Surg 2004;77:1763-1768.
19 LeBlanc JK, Devereaux BM, Imperiale TF, Kesler K, DeWitt JM, Cummings O, Ciaccia D, Sherman S, Mathur P, Conces D, Brooks J, Chriswell M, Einhorn L, Collins E: Endoscopic ultrasound in non-small cell lung cancer and negative mediastinum on computed tomography. Am J Respir Crit Care Med 2005;171:177-182.

20 Fernandez-Esparrach G, Gines A, Belda J, Pellise M, Sole M, Marrades R, Sendino O, Colomo L, Mata A, Llach J, Bordas JM, Castells A: Transesophageal ultrasound-guided fine needle aspiration improves mediastinal staging in patients with non-small cell lung cancer and normal mediastinum on computed tomography. Lung Cancer 2006;54: $35-40$.

21 Eloubeidi MA, Cerfolio RJ, Chen VK, Desmond R, Syed S, Ojha B: Endoscopic ultrasound-guided fine needle aspiration of mediastinal lymph node in patients with suspected lung cancer after positron emission tomography and computed tomography scans. Ann Thorac Surg 2005;79:263-268.

22 Mountain CF: Revisions in the international system for staging lung cancer. Chest 1997; 111:1710-1717.

23 Mountain CF, Dresler CM: Regional lymph node classification for lung cancer staging. Chest 1997;111:1718-1723.

24 Kiyono K, Sone S, Sakai F, Imai Y, Watanabe T, Izuno I, Oguchi M, Kawai T, Shigematsu $\mathrm{H}$, Watanabe M: The number and size of normal mediastinal lymph nodes: a postmortem study. AJR Am J Roentgenol 1988;150:771776.

25 Kramer H, van Putten JW, Douma WR, Smidt AA, van Dullemen HM, Groen HJ: Technical description of endoscopic ultrasonography with fine-needle aspiration for the staging of lung cancer. Respir Med 2005;99: 179-185.

26 Catalano MF, Sivak MV Jr, Rice T, Gragg LA, Van Dam J: Endosonographic features predictive of lymph node metastasis. Gastrointest Endosc 1994;40:442-446.

27 Bhutani MS, Hawes RH, Hoffman BJ: A comparison of the accuracy of echo features during endoscopic ultrasound (EUS) and EUS-guided fine-needle aspiration for diagnosis of malignant lymph node invasion. Gastrointest Endosc 1997;45:474-479. 
-28 Fernandez-Villar A, Leiro V, Blanco M, Represas C, Botana M, Gonzalez A, Pineiro L: Efficacy and safety of the excelon transbronchial aspiration needle in mediastinal lymph node enlargement: a case-control study. Respiration 2007;74:208-213.

-29 Hermens FH, Limonard GJ, Termeer R, van den Berg W, Visser FJ, Hol BE, Janssen JP: Learning curve of conventional transbronchial needle aspiration in pulmonologists experienced in bronchoscopy. Respiration 2008;75:189-192.

>30 Kuzdzal J, Zielinski M, Papla B, Urbanik A, Wojciechowski W, Narski M, Szlubowski A, Hauer L: The transcervical extended mediastinal lymphadenectomy versus cervical mediastinoscopy in non-small cell lung cancer staging. Eur J Cardiothorac Surg 2007;31: 88-94.
1 Witte B, Hurtgen M: Video-assisted mediastinoscopic lymphadenectomy (VAMLA). J Thorac Oncol 2007;2:367-369.

-32 Wallace MB, Kennedy T, Durkalski V, Eloubeidi MA, Etamad R, Matsuda K, Lewin D, Van Velse A, Hennesey W, Hawes RH, Hoffman BJ: Randomized controlled trial of EUS-guided fine needle aspiration techniques for the detection of malignant lymphadenopathy. Gastrointest Endosc 2001;54 441-447.

33 Krasnik M: Endoscopic transesophageal and endoscopic transbronchial real-time ultrasound-guided biopsy. Respiration 2003;70: 293-298.

34 Yasufuku K, Nakajima T, Motoori K, Sekine Y, Shibuya K, Hiroshima K, Fujisawa T: Comparison of endobronchial ultrasound, positron emission tomography, and CT for lymph node staging of lung cancer. Chest 2006;130:710-718.
35 Vilmann P, Krasnik M, Larsen SS, Jacobsen GK, Clementsen P: Transesophageal endoscopic ultrasound-guided fine-needle aspiration (EUS-FNA) and endobronchial ultrasound-guided transbronchial needle aspiration (EBUS-TBNA) biopsy: a combined approach in the evaluation of mediastinal lesions. Endoscopy 2005;37:833-839.

36 Wallace MB, Pascual JM, Raimondo M, Woodward TA, McComb BL, Crook JE, Johnson MM, Al-Haddad MA, Gross SA, Pungpapong S, Hardee JN, Odell JA: Minimally invasive endoscopic staging of suspected lung cancer. JAMA 2008;299:540546. 